\title{
Impact of Comorbidities on Self-Esteem of Children with Attention Deficit Hyperactivity Disorder
}

\author{
Pradeep Palaniappan ${ }^{1 *}$
}

\section{ABSTRACT}

Background: 2 decades of research had found that comorbid disorders occur in children with ADHD more than by chance. The role of comorbidities in influencing the self-esteem of children with ADHD is still less explored. Aims: To study the various domains of self-esteem in children with ADHD and to evaluate the effect of comorbidities on low self-esteem in ADHD children. Methods And Materials: 60 subjects aged 6 to 16 years who were diagnosed based on DSM IV as ADHD were recruited with informed consent, from tertiary care hospital for a period of 6 months by consecutive sampling. Based on detailed interview of subjects and parents using the Semi structured assessment schedule K- SADS - PL for comorbidities, children with ADHD were grouped as those with and without comorbidities. While severity of ADHD was assessed by Conner's Parent's 10 item abbreviated index, self-esteem was assessed by Culture free selfesteem inventory. Results: Parent related self-esteem was lower in ADHD children with comorbid internalizing disorders when compared to ADHD children with comorbid externalizing disorders. Higher severity of ADHD and longer duration of ADHD correlated with lower selfesteem, (especially social domain). Conclusions: Comorbidities definitely influence the level of self-esteem in children with ADHD, but other factors also need to be considered for optimal management of low self-esteem.

Keywords: Attention Deficit Hyperactivity Disorder, ADHD, Comorbidity, Self-Esteem

ADHD is a condition characterized by varying levels of inattention, hyperactivity, and impulsivity with significant academic, social, and emotional problems at many settings like home and school. Worldwide pooled prevalence of ADHD is 5.29\% [1], with large variability of prevalence rates resulting from usage of different diagnostic criterion and impairment criterion. Prevalence of ADHD in India ranges from $1.6 \%$ to $14 \%$ across various studies [2]. Studies on prevalence of ADHD in Indian children in Paediatric [3,4] and Psychiatric [5,6] outpatient

\footnotetext{
${ }^{1}$ Assistant professor, Department of Psychiatry, PSG Institute of Medical Sciences \& Research, Coimbatore, Tamil Nadu, India.

*Responding Author

(C) 2016 I P Palaniappan; licensee IJIP. This is an Open Access Research distributed under the terms of the Creative Commons Attribution License (http://creativecommons.org/licenses/by/2.0), which permits unrestricted use, distribution, and reproduction in any Medium, provided the original work is properly cited.
} 
services had been done in the past decade which had reported that children with ADHD had significant academic(60\%) and peer(75\%) related problems [6].

Self-esteem has been defined as a cognitive and emotional concept of an individual has about himself. There has been a growing consensus that self-esteem is often neglected in ADHD which is multidimensional in construct. It is based on the assumption that the self-concept is based on the ratio between perceived competence and the person's aspirations in any one specific area of life. One's overall sense of worth is constructed on the basis of competencies in those areas one considers important [9]. Discrepancies between perceived competence and the importance to succeed in that particular area, as acknowledged by one self and by other important people, put the person at risk for impairment in self-esteem.

Low Self-esteem (50\%), interference of family functioning (50\%), interference of academic (50\%) \& social functioning (25\%) were perceived by parents of children with ADHD, which were statistically significant when compared to healthy controls $[7,8]$. In prospective studies, adolescents with ADHD on follow up had been found to have similar low self-esteem when compared to non-disordered population [9]. There are also some studies which show no correlation between ADHD \& self-esteem [10].

Aggressive boys with attention-deficit/hyperactivity disorder (ADHD) showed higher rates of depressive symptomatology and lower levels of self-esteem than would non aggressive ADHD boys [11]. Though $75 \%$ of the children with comorbid behavior pattern of hyperactivityimpulsivity-inattention and conduct problems (HIA + CP) were rejected by their peers and had no reciprocated friendships compared to one-third of the children with internalizing and externalizing behavior pattern ( + E), the HIA + CP and I + E groups showed average levels of academic self-concept and did not differ from controls on measures of social self-concept and academic self-concept and general self-esteem [12,18]. These contradictory results may be secondary to positive illusionary self-concepts held by these children [13].

Though a lot of literature already exists, there are few studies in Indian children especially looking at the self-esteem in this vulnerable group of children. Further there are paucity of research on effect of ADHD and its comorbidities on various domains of self-esteem in children with ADHD.

Keeping all these into consideration, we conducted this study with the aim

1. To assess various domains of self-esteem in children with ADHD

2. To assess the effect of comorbidities on self-esteem of children with ADHD

\section{MATERIALS AND METHODS}

Children and Adolescents of age 6 to 16 years of either sex who came to Child and Adolescent Psychiatry Out-patient clinic of tertiary care hospital were screened (Consequent sampling) for presence of ADHD (current or past). Children with progressive neurodegenerative conditions, Mental retardation, Pervasive developmental disorders and sensory deficits of sufficient severity 
to cause hyperactivity were excluded from the study. Diagnosis of ADHD using DSM IV-TR was confirmed either by Consultants or by Senior Residents of Child Psychiatry Services in the tertiary care hospital. The study was conducted after institutional ethical committee clearance. With prior informed consent, data on socio-demographic details and comorbidity (using Kiddie SADS-PL) were collected from 60 children with ADHD who fulfilled inclusion and exclusion criteria. Severity of ADHD was assessed using Conner's ADHD severity index in all 60 subjects. Culture Free Self Esteem inventory (CFSEI), a self-esteem inventory was used to evaluate various sub domains of self-esteem i.e.; general, academic, social and parent related self- esteem domains.

\section{Statistical Analysis:}

Comparison between the groups (ADHD children without comorbidity, ADHD children with comorbid internalizing disorders, ADHD children with comorbid externalizing disorders) were done using Chi Square test for discrete variables and independent student ' $t$ ' test for continuous variables. Pearson's correlation was used to evaluate correlation between illness characteristics like Age of onset of ADHD and comorbidities, Duration of ADHD, severity of ADHD and selfesteem. All data were analysed using Statistical Package for Social Sciences (SPSS) 19.0 version.

\section{RESULTS}

Mean age of 60 subjects was $9 \pm 3.39$ years. Subjects were predominantly boys (86\%) (Table 1)and belong to middle socioeconomic status(45\%). The recruited subjects were equally from urban (48.3\%) \& rural (51.7\%) background. Mean duration of ADHD being $5.25 \pm 2.15$ years. Mean Conner's ADHD severity index score was $14.02 \pm 4.66$ implying that the recruited subjects predominantly had mild severity of ADHD. 55\% $(n=33)$ of recruited subjects had a comorbidity, with highly prevalent comorbid disorder being disruptive disorders(38.3\%), followed by mood disorders(15\%) and then, anxiety disorder(11\%), Substance use disorders(8\%), Tic disorders(5\%) and elimination disorders(3.3\%).

On comparison of various domains of self-esteem among children with and without comorbidity, ADHD children with comorbid internalizing disorders (Mood disorders and anxiety disorders) scored very low (statistically significant) in parent related self-esteem (Table2). In ADHD children without comorbidities, lower social self-esteem was significantly correlated with earlier age of onset of ADHD, longer duration of ADHD and higher severity of ADHD (Table 3). In Children with comorbid internalizing disorders, earlier age of onset of ADHD was correlated with lower social and global domains of self-esteem (Table 4). In children with comorbid externalizing disorders (disruptive disorders), higher severity of ADHD was correlated with lower social, academic and global domains of self-esteem. Additionally, in these children with comorbid externalizing disorders, duration of externalizing disorders was correlated with lower general and parent related self-esteem (Table 5). 


\section{DISCUSSION}

In this current study, Low self-esteem was related to increasing age of the children, possibly reflecting better perception of poor self-esteem along the development trajectory[14]; earlier age of onset of ADHD, earlier age of onset of comorbid disorders, prolonged duration of ADHD \& comorbid disorders probably reflecting the deranged internalization of self-concept secondary to ADHD related social, peer, academic dysfunction during the early childhood [15]; severity of ADHD, depression and anxiety [11,16].

Earlier age of onset of ADHD, prolonged duration of ADHD, severity of ADHD significantly correlated with poor social self-esteem than other spheres of self-esteem in ADHD children. This association needs more attention, when it is known peer relationships in early childhood are the primary context in which children learn skills like cooperation, negotiation, and conflict resolution that are critical for effective social functioning [14].These children with ADHD face more peer rejection, were lower on social preference, higher on social impact, less well-liked, and had fewer dyadic friendships; were disliked by children of higher status within the peer group, suggesting a process of exclusion by more popular peers throughout life [17].

Comparison of various domains of self-esteem in various groups of ADHD in this study showed that children with comorbid internalizing disorders had poorer parent related self-esteem when compared to other groups. This in contrast to previous study[16], in which total self-esteem was found to be very low for children with internalizing disorders when compared to children with no comorbidity and externalizing disorders. Several factors like race, special education population, difference in age and sample recruitment can explain these differences [19].

The association between poorer parent related self-esteem in children with internalizing disorders need more exploration[11, 20], but could be related to psychosocial adversities in form of hostility towards the child, which was noted to be high in this group, when compared with children of other subgroup. But oversimplification to such an association needs to be taken with caution and more structured studies looking for a relation between psychosocial adversities and self-esteem will answer this association.

The study has some limitations. First, this being a cross sectional study, onetime assessment may not be the ideal for assessment of self esteem as it is known to evolve few years later. Second, Confounders of low self esteem like age, psychosocial adversities, temperament, and gender had not been controlled. Future studies controlling for confounding variables would help to exactly measure the impact of comorbidities on self esteem of ADHD children. Third, effect of each comorbidity on the self esteem can't be quantified with this methodology, which may need a different approach. Fourth, sample size is small and thus needs to be confirmed with a larger sample.

In conclusion, comorbidities do have a heavy impact on the self-esteem of the ADHD children but, comorbidities alone may not be the sole reason for low self-esteem, rather other factors which should also be considered are severity of ADHD and duration of ADHD. 


\section{REFERENCES}

1. Polanczyk, G., et al.,(2007). The worldwide prevalence of ADHD: a systematic review and metaregression analysis. Am J Psychiatry. 164(6): p. 942-8.

2. Srinath, S., et al., (2005) Epidemiological study of child \& adolescent psychiatric disorders in urban \& rural areas of Bangalore, India. Indian J Med Res. 122(1): p. 67-79.

3. Bhatia, M.S., et al., (1991). Attention deficit disorder with hyperactivity among paediatric outpatients. J Child Psychol Psychiatry, 32(2): p. 297-306.

4. Mukhopadhyay, M., et al., (2003). Attention deficit hyperactivity disorder. Indian J Pediatr, 70(10): p. 789-92.

5. Bhatia, M.S., S. Choudhary, A. Sidana.(1999). Attention deficit hyperactivity disorder among psychiatric outpatients. Indian Pediatr. 36(6): p. 583-7.

6. Malhi. P, Singhi P. (2000). Spectrum of attention deficit hyperactivity disorders in children among referrals to psychology services. Indian Pediatr, 37(11): p. 1256-60

7. Sawyer, M. G., Whaites, L., Rey, J. M., et al (2002) Health-related quality of life of children and adolescents with mental disorders. J Am Acad Child Adolesc Psychiatry, 41, 530-537

8. Hechtman, L., Weiss, G. \& Perlman, T. (1980) Hyperactives as young adults: self-esteem and social skills. Can J Psychiatry, 25, 478-483.

9. Slomkowski, C., Klein, R. G. \& Mannuzza, S. (1995) Is self-esteem an important outcome in hyperactive children? J Abnorm Child Psychol, 23, 303-315.

10. Hoza, B., Pelham, W. E., Milich, R., et al (1993) The self-perceptions and attributions of attention deficit hyperactivity disordered and nonreferred boys. J Abnorm Child Psychol, 21, 271-286.

11. Treuting, J. J. \& Hinshaw, S. P. (2001) Depression and self-esteem in boys with attention-deficit/hyperactivity disorder: associations with comorbid aggression and explanatory attributional mechanisms. J Abnorm Child Psychol, 29, 23-39.

12. Gresham, F. M., MacMillan, D. L., Bocian, K. M., et al (1998) Comorbidity of hyperactivity-impulsivity-inattention and conduct problems: risk factors in social, affective, and academic domains. J Abnorm Child Psychol, 26, 393-406.

13. Hoza, B., Pelham, W. E., Jr., Dobbs, J., et al (2002) Do boys with attentiondeficit/hyperactivity disorder have positive illusory self-concepts? J Abnorm Psychol, 111, 268-278

14. Hoza, B. (2007) Peer functioning in children with ADHD. J Pediatr Psychol, 32, 655-663.

15. Zarin, D. A., Suarez, A. P., Pincus, H. A., et al (1998) Clinical and treatment characteristics of children with attention-deficit/hyperactivity disorder in psychiatric practice. J Am Acad Child Adolesc Psychiatry, 37, 1262-1270.

16. Bussing, R., Zima, B. T. \& Perwien, A. R. (2000) Self-esteem in special education children with ADHD: relationship to disorder characteristics and medication use. $\mathrm{J}$ Am Acad Child Adolesc Psychiatry, 39, 1260-1269.

17. MTA Cooperative group.(1999). A 14-month randomized clinical trial of treatment strategies for attention-deficit/hyperactivity disorder. The MTA Cooperative Group. 
Multimodal Treatment Study of Children with ADHD. Arch Gen Psychiatry, 56, 10731086.

18. Treuting JJ.(2001) Depression and self-esteem in boys with attention deficit/ hyperactivity disorder: associations with comorbid aggression and explanatory attributional mechanisms. J Abnorm Child Psychol ; 29: 23_39.

19. Bussing R, Zima BT, Perwien AR.(2000). Self-esteem in special education children with ADHD: relationship to disorder characteristics and medication use. J Am Acad Child Adolesc Psychiatry 39: 1260_9.

20. Diener, M. B.,Milich, R. (1997). Effects of positive feedback on the social interactions of boys with attention deficit hyperactivity disorder: A test of the self-protective hypothesis. Journal of Clinical Child Psychology 26, 256-265. 
Impact of Comorbidities on Self-Esteem of Children with Attention Deficit Hyperactivity Disorder

Table 1: Baseline characteristics of children with ADHD:

\begin{tabular}{|c|c|c|c|c|}
\hline Characteristics & Total $(n=60)$ & $\begin{array}{l}\text { Without } \\
\text { Comorbidity( } n=27)\end{array}$ & $\begin{array}{l}\text { With comorbidity } \\
(\mathrm{n}=33)\end{array}$ & P value \\
\hline $\begin{array}{l}\text { Age of child } \\
\text { (years)* }\end{array}$ & $9.00 \pm 3.38$ & $6.89 \pm 1.99$ & $10.73 \pm 3.33$ & $<0.001$ \\
\hline \multicolumn{5}{|l|}{ Age Group* } \\
\hline 6-9 years & 40 & $26(65 \%)$ & $14(35 \%)$ & \multirow[t]{2}{*}{$<0.001$} \\
\hline 10-16 years & 20 & $1(5 \%)$ & 19 (95\%) & \\
\hline \multicolumn{5}{|l|}{ Gender } \\
\hline Male & $52(86 \%)$ & 23 & 29 & \multirow[t]{2}{*}{0.52} \\
\hline Female & $8(14 \%)$ & 4 & 4 & \\
\hline \multicolumn{5}{|c|}{ Socio economic status } \\
\hline Lower & 12 & $7(58 \%)$ & $5(42 \%)$ & \multirow[b]{3}{*}{0.16} \\
\hline Middle & 27 & $14(51 \%)$ & $13(49 \%)$ & \\
\hline Higher & 21 & $6(28 \%)$ & $15(72 \%)$ & \\
\hline \multicolumn{5}{|l|}{ Domicile } \\
\hline Urban & 29 & $15(51 \%)$ & $14(49 \%)$ & \multirow[t]{2}{*}{0.31} \\
\hline Rural & 31 & 12 (38\%) & $19(62 \%)$ & \\
\hline
\end{tabular}

Table 2: Comparison of CFSEI domain scores in various groups of ADHD children:

\begin{tabular}{|l|l|l|l|l|l|}
\hline $\begin{array}{l}\text { CFSEI } \\
\text { domain } \\
\text { scores }\end{array}$ & $\begin{array}{l}\text { ADHD } \\
\text { without } \\
\text { comorbidity }\end{array}$ & $\begin{array}{l}\text { ADHD with } \\
\text { internalizing } \\
\text { disorders }\end{array}$ & $\begin{array}{l}\text { ADHD with } \\
\text { externalizing } \\
\text { disorders }\end{array}$ & F & $\begin{array}{l}\text { Statistical } \\
\text { significance }\end{array}$ \\
\hline General & $9.74 \pm 3.3$ & $8.32 \pm 3.5$ & $9.71 \pm 3.75$ & 1.088 & 0.344 \\
\hline Social & $3.26 \pm 1.72$ & $3.89 \pm 1.97$ & $3.43 \pm 2.1$ & 0.647 & 0.527 \\
\hline Academic & $3.59 \pm 1.92$ & $3.16 \pm 1.65$ & $3.00 \pm 2.07$ & 0.553 & 0.578 \\
\hline Parent & $6.59 \pm 2.11$ & $4.74 \pm 2.07$ & $5.36 \pm 2.06$ & 0.658 & $0.013^{*}$ \\
\hline Global & $6.57 \pm 1.26$ & $6.66 \pm 1.52$ & $7.44 \pm 1.99$ & 0.97 & 0.385 \\
\hline
\end{tabular}

* - Statistically significant, $\mathbf{p}<0.05$ 
Impact of Comorbidities on Self-Esteem of Children with Attention Deficit Hyperactivity Disorder

Table 3: Correlation between Self-esteem and Illness characteristics in ADHD children without comorbidity:

\begin{tabular}{|l|c|c|c|c|}
\hline $\begin{array}{c}\text { CFSEI } \\
\text { Domain } \\
\text { Scores }\end{array}$ & $\begin{array}{c}\text { Age of the } \\
\text { Child }\end{array}$ & $\begin{array}{c}\text { Age of onset of } \\
\text { ADHD }\end{array}$ & $\begin{array}{c}\text { Duration of } \\
\text { ADHD }\end{array}$ & $\begin{array}{c}\text { Severity of } \\
\text { ADHD - } \\
\text { Conner's }\end{array}$ \\
\hline General & 0.23 & $0.38^{*}$ & $-0.35^{*}$ & -0.30 \\
\hline Social & $0.42^{*}$ & $0.30^{*}$ & $-0.42^{*}$ & $-0.55^{*}$ \\
\hline Academic & 0.58 & 0.18 & -0.11 & -0.20 \\
\hline Parent & $-0.40^{*}$ & 0.23 & -0.33 & 0.10 \\
\hline Global & 0.12 & 0.30 & -0.21 & -0.32 \\
\hline
\end{tabular}

* - Statistically significant, $\mathrm{p}<\mathbf{0 . 0 5}$

Table 4: Correlation between Self-esteem and illness characteristics in ADHD children with comorbid internalizing disorders:

\begin{tabular}{|l|c|c|c|c|c|c|}
\hline \multicolumn{1}{|c|}{ Scores } & $\begin{array}{c}\text { Age of } \\
\text { Child }\end{array}$ & $\begin{array}{c}\text { Age of } \\
\text { onset of } \\
\text { ADHD }\end{array}$ & $\begin{array}{c}\text { Duration } \\
\text { of ADHD }\end{array}$ & $\begin{array}{c}\text { Severity } \\
\text { of } \\
\text { ADHD- } \\
\text { Conner's }\end{array}$ & $\begin{array}{c}\text { Age of onset } \\
\text { of } \\
\text { Internalizing }\end{array}$ & $\begin{array}{c}\text { Duration of } \\
\text { Internalizing } \\
\text { disorder }\end{array}$ \\
\hline $\begin{array}{l}\text { CFSEI } \\
\text { General }\end{array}$ & -0.21 & 0.40 & -0.27 & -0.18 & -0.20 & -0.09 \\
\hline $\begin{array}{l}\text { CFSEI } \\
\text { Social }\end{array}$ & -0.14 & $0.51^{*}$ & -0.23 & -0.41 & -0.003 & -0.17 \\
\hline $\begin{array}{l}\text { CFSEI } \\
\text { Academic }\end{array}$ & -0.17 & 0.16 & -0.20 & -0.20 & -0.26 & -0.37 \\
\hline $\begin{array}{l}\text { CFSEI } \\
\text { Parent }\end{array}$ & -0.12 & 0.44 & -0.20 & -0.08 & -0.26 & -0.32 \\
\hline $\begin{array}{l}\text { CFSEI } \\
\text { Global }\end{array}$ & -0.25 & $0.64 *$ & -0.35 & -0.29 & -0.12 & -0.36 \\
\hline
\end{tabular}

* - Statistically significant, $\mathrm{p}<\mathbf{0 . 0 5}$ 
Impact of Comorbidities on Self-Esteem of Children with Attention Deficit Hyperactivity Disorder

Table 5: Correlation between Self-esteem and illness characteristics in ADHD children with comorbid externalizing disorders:

\begin{tabular}{|l|c|c|c|c|c|c|}
\hline \multicolumn{1}{|c|}{ Scores } & Age of & $\begin{array}{c}\text { Age of } \\
\text { onset of } \\
\text { ADHD }\end{array}$ & $\begin{array}{c}\text { Duration } \\
\text { of ADHD }\end{array}$ & $\begin{array}{c}\text { Severity of } \\
\text { ADHD- } \\
\text { Conner's }\end{array}$ & $\begin{array}{c}\text { Age of onset } \\
\text { of Non } \\
\text { intern } \\
\text { disorders }\end{array}$ & $\begin{array}{c}\text { Duration of } \\
\text { Non Intern }\end{array}$ \\
\hline $\begin{array}{l}\text { CFSEI } \\
\text { General }\end{array}$ & $0.47^{*}$ & 0.12 & $-0.46^{*}$ & -0.28 & 0.32 & $-0.41^{*}$ \\
\hline $\begin{array}{l}\text { CFSEI } \\
\text { Social }\end{array}$ & 0.37 & 0.30 & 0.33 & $-0.59 *$ & $0.53 \dagger$ & 0.12 \\
\hline $\begin{array}{l}\text { CFSEI } \\
\text { Academic }\end{array}$ & 0.27 & 0.05 & 0.29 & $-0.44^{*}$ & 0.35 & 0.09 \\
\hline $\begin{array}{l}\text { CFSEI } \\
\text { Parent }\end{array}$ & -0.09 & 0.23 & -0.14 & -0.28 & 0.15 & $-0.28 *$ \\
\hline $\begin{array}{l}\text { CFSEI } \\
\text { Global }\end{array}$ & 0.37 & 0.19 & 0.35 & $-0.46^{*}$ & $0.44^{*}$ & 0.17 \\
\hline
\end{tabular}

* - Statistically significant, $\mathbf{p}<\mathbf{0 . 0 5}$ 